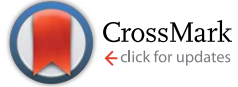

Cite this: RSC Adv., 2015, 5, 22947

Received 26th December 2014 Accepted 24th February 2015

DOI: $10.1039 / c 4 r a 17107 a$

\section{Phenothiazine-functionalized redox polymers for a new cathode-active material $\uparrow$}

\author{
Ali A. Golriz, ${ }^{\text {ab }}$ Takeo Suga, ${ }^{\star c}$ Hiroyuki Nishide, ${ }^{* d}$ Rüdiger Berger ${ }^{a}$ \\ and Jochen S. Gutmann*be
}

www.rsc.org/advances

Redox-active, phenothiazine-functionalized polymers were synthesized and employed as a promising cathode-active material $(\sim 3.7 \mathrm{~V}$ vs. $\mathrm{Li}, 77 \mathrm{Ah} \mathrm{kg}^{-1}$ ) in a rechargeable battery. The longer spacer between phenothiazine and the polymer backbone contributed to the stability of the formed radical cations, resulting in decelerated self-discharge and improved cycle performance.

Electro-active polymers bearing redox-active pendant groups such as triphenylamine, carbazole, and nitroxide, etc. have attracted renewed attention in energy-storage and opto-/electronics applications. ${ }^{1,2}$ The phenothiazine unit, a wellknown hetero-tricyclic structure in methylene blue, photo-sensitizers, ${ }^{3}$ photo-polymerization catalysts, ${ }^{4}$ and pharmacological agents, ${ }^{5}$ has been also proposed as a key constituent for the hole-transporting layer in polymer light emitting diodes (PLED), ${ }^{6}$ for electrocatalysts in biosensors, ${ }^{7}$ and for electrochromic materials in electronic displays. ${ }^{8}$ At molecular basis, such superior electronic characteristics lies in the redox chemistry of phenothiazine units. ${ }^{9,10}$ The oxidation of the neutral phenothiazine leads to the formation of persistent radical cation species, and their $\pi-\pi$ stacking results in enhanced electric conductivity. ${ }^{\mathbf{1 1}}$ Remarkable is the stability of both neutral and cationic states $(>50 \mathrm{~h})$. We have successfully demonstrated that a thin film of poly-3-vinylbenzylphenothaizine can be used as a bias-responsive

${ }^{a}$ Max Planck Institute for Polymer Research, Ackermannweg 10, D-55128 Mainz, Germany. E-mail: berger@mpip-mainz.mpg.de; Fax: +49-6131-379-100; Tel: +496131-379-114

${ }^{b}$ Department of Chemistry and Center for Nanointegration Duisburg-Essen (CENIDE), University Duisburg-Essen, Universitätsstr. 5, D-45117 Essen, Germany. E-mail: jochen.gutmann@uni-due.de; Fax: +49-201-183-4934; Tel: +49-201-183-2566

${ }^{c}$ Waseda Institute for Advanced Study, Waseda University, Tokyo 169-8555, Japan. E-mail: takeosuga@toki.waseda.jp

${ }^{d}$ Department of Applied Chemistry, Waseda University, Tokyo, 169-8555, Japan. E-mail: nishide@waseda.jp; Fax: +81-3-3209-5522; Tel: +81-3-3200-2669

${ }^{e}$ Deutsches Textilforschungszentrum Nord-West e.V., Adlerstr. 1, D-47798 Krefeld, Germany

$\dagger$ Electronic supplementary information (ESI) available: Details of the synthetic preparation and electrochemical characterization. See DOI: 10.1039/c4ra17107a bistable media for data storage. ${ }^{12,13}$ On a spin-coated layer of phenothiazine-based polymers, nano-patterns with enhanced conductivity were recorded via conductive scanning force microscopy, ${ }^{14}$ and conductive states (cations) were stored for several days. Furthermore, grafted polymer brushes for phenothiazine polymers were developed to obtain redox-active surfaces with increased nanowear stability. ${ }^{15,16}$

Such long-term durability of phenothiazine radical cations at a solid-state (without electrolyte) has evoked renewed attention in their potential electrochemical applications, where the redox process can be supported/stabilized in presence of electrolytes. Recent progress in utilizing redox polymers for electrode-active materials in a rechargeable battery has been demonstrated by Nishide. ${ }^{17,18}$ Nitroxide-functionalized polymers were employed as cathode-active material to give the cell voltage of $3.5 \mathrm{~V} v s . \mathrm{Li} /$ $\mathrm{Li}^{+}$, relatively high charge capacity $\left(110 \mathrm{~mA} \mathrm{~h} \mathrm{~g}{ }^{-1}\right)$, high powerrate performance (rapid charging), and long cycle life (>1000 cycles). Other redox-active organic groups such as benzoquinones, $^{19}$ heteroaromatic derivatives ${ }^{20}$ have been reexamined in terms of charge-storage capability. Phenothiazine is a promising candidate for a new cathode-active material to show more positive oxidation potential, which leads to higher cell voltage. Enhanced conductivity based on $\pi-\pi$ stacking of closely immobilized phenothiazine side groups promises associated conductivity besides on redox conduction. Phenothiazine-based polymers can be prepared in a facile conventional radical polymerization, compared with non-trivial synthesis of radical polymers, which often requires the protecting groups or precursors for the polymerization steps. ${ }^{21,22}$ There are a few previous reports dealing with electrochemical properties of phenothiazine-based polymers, ${ }^{23}$ but here we report synthesis and electrochemical properties of phenothiazine polymers in view of their application to cathode-active materials in a lithium-ion battery. In particular, we synthesize phenothiazine-functionalized polymers with different alkyl spacer lengths, poly(10-(4-vinylbenzyl)-10H-phenothiazine) (PVBPT) and poly(10-(3-(4-vinylphenyl)propyl)-10H-phenothiazine) (PVPPP), and elucidate whether the spacer plays a key role 
for tuning the redox stability, which closely related to selfdischarge behaviour and cycle performance of the battery.

Phenothiazine-functionalized polymers, PVBPT $\left(M_{\mathrm{n}}=273000\right.$, PDI $\left.=2.32\right)$ and PVPPP $\left(M_{\mathrm{n}}=25800\right.$, PDI $=1.96)$ were synthesized via conventional radical polymerization from the corresponding monomers in anisole or THF using AIBN (1 mol\%) as an initiator (Fig. 1). Detailed synthetic procedures were shown in the ESI. $\dagger$ The obtained polymers were spin-coated on an indium tin oxide (ITO) electrode (thickness $\sim 100-150 \mathrm{~nm}$ ) and used for electrochemical characterizations.

Cyclic voltammograms for PVBPT and PVPPP films on ITO exhibited reversible redox waves at $E_{0}=0.87$ and $0.84 \mathrm{~V} v s$. $\mathrm{Ag} / \mathrm{AgCl}$, respectively (Fig. $2 \mathrm{a}$ and b). Formation of the radical cation species was examined via electron spin resonance (ESR) spectroscopy combined with CV. The oxidation of PVPPP at 1.1 V formed an ESR signal at $g=2.0049$, (2.0052 reported for benzylphenothiazine), ${ }^{24}$ which suggested the free electron is delocalized through the aromatic ring systems, and appeared as carbon-centered radicals. The broadening of the signal was explained by the high local concentration of radical species along the backbone. The ESR signal disappeared after applying potential at $0.5 \mathrm{~V}$, which demonstrated the reversible reduction of the radical cation to the neutral state (Fig. 2 inset).

The separation between oxidation and reduction peaks, $\Delta E_{\mathrm{p}}$, for PVBPT slightly increased from 48 to $67 \mathrm{mV}$ at increasing scan rates from 1 to $20 \mathrm{mV} \mathrm{s}^{-1}$, and the linear plots of the measured peak currents against the scan rates for the anodic (or cathodic) scans indicated the reversible redox characteristics for the surface-confined redox species (Fig. 2c). PVPPP exhibited an increased peak-to-peak separations at scan rates $\geq$ $10 \mathrm{mV} \mathrm{s}^{-1}$. An anodic peak current obtained at a scan rate of $20 \mathrm{mV} \mathrm{s}^{-1}$ deviated from a linear correlation between peak currents vs. scan rates, which suggested slower redox process for PVPPP film.

The electron transfer kinetics through the film was further investigated by chronoamperometry (CA) measurements. The apparent diffusion coefficients, $D_{\text {app }}$, of electron transfer through the PVBPT and PVPPP films were estimated from the Cottrell plots (Fig. 2d) to be $1.5 \times 10^{-9}$ and $1.0 \times 10^{-10}$ $\left(\mathrm{cm}^{2} \mathrm{~s}^{-1}\right)$, respectively, based on an equation of $i=n F D_{\text {app }}{ }^{1 / 2} \mathrm{C}^{*} /$ $\pi^{1 / 2} t^{1 / 2} \cdot{ }^{25}$ Both values are in good agreement with the reported values from the literature. ${ }^{24}$ From the calculated values for $D_{\text {app }}$
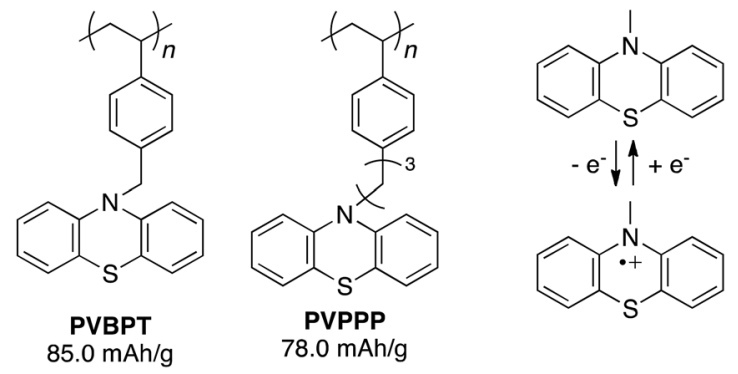

Fig. 1 Chemical structure of phenothiazine-functionalized polymers and the redox couple between phenothiazine and its radical cation.
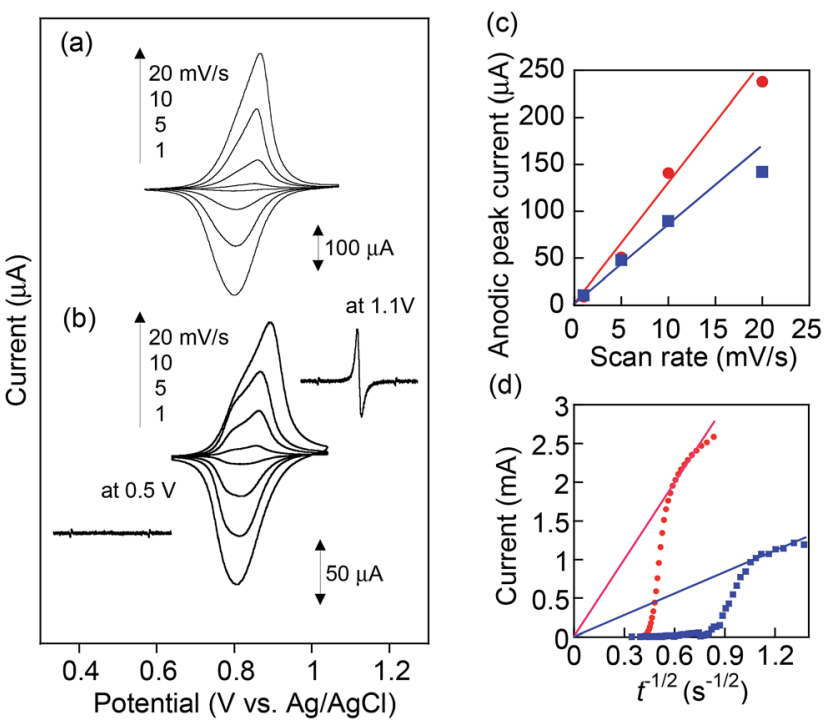

Fig. 2 Cyclic voltammograms of (a) PVBPT and (b) PVPPP spin-coated on indium tin oxide (ITO) as a working electrode. Inset: in situ electrolytic ESR spectra under the applied potentials. (c) Anodic peak currents vs. scan rates and (d) Cottrell plots for PVBPT (red) and PVPPP (blue).

we estimated the electron exchange rate $k_{\text {ex }}$ using the DahmsRuff equation: $k_{\text {ex }}=4 D_{\text {app }} /\left(\pi \delta^{2} C_{\text {redox }}^{*}\right) .^{26}$ The estimation requires the center-to-center distance $\delta$ of the redox moieties in the polymer chain $(\approx 5 \AA)$ and the concentration of the redox species at the electrode interface $C_{\text {redox }}^{*}$, which was calculated from the CA data. A faster electron self-exchange rate, $k_{\text {ex }}$ for PVBPT was obtained to be $1.6 \times 10^{6} \mathrm{M}^{-1} \mathrm{~s}^{-1}$ compared with that of PVPPP $\left(4.9 \times 10^{4} \mathrm{M}^{-1} \mathrm{~s}^{-1}\right)$, which suggested long alkyl spacer group between phenothiazine and polymer backbone enabled more rotational freedom for the aromatic rings to get in the proper juxtaposition for electron exchange. In PVPPP, the redox moieties were separated from each other so that the interaction between them was aggravated and the rotation process involved additional activation. This results in a reduced the electron self-exchange rate.

The chemical stability of the oxidized state (radical cations) for PVBPT and PVPPP was studied by in situ electrochemical UV and ESR spectroscopy. The oxidation process was accompanied by reversible color change from colorless to dark red (Fig. 3b, inset). The first absorption maximum at $518 \mathrm{~nm}$ corresponded to the absorption bands for the phenothiazine radical cation, and the second absorption band at $859 \mathrm{~nm}$ corresponded to the formation of a dimer with a face-to-face orientation of the radical cation species (Fig. 3 ). ${ }^{27,28}$ The stronger absorption peak at 800-900 $\mathrm{nm}$ for oxidized PVBPT compared with oxidized PVPPP suggested facile dimer formation of phenothiazine cations due to the short spacer groups, which also supported the electron transfer kinetics. After oxidation, the bias was turned off, and the UV spectral change for both polymers was monitored (Fig. 3a and b). The absorption peaks at $518 \mathrm{~nm}$ decreased over time for PVBPT, and relative absorbance after 60 min was $60 \%$ (Fig. 3c). Re-oxidation of PVBPT exhibited the 

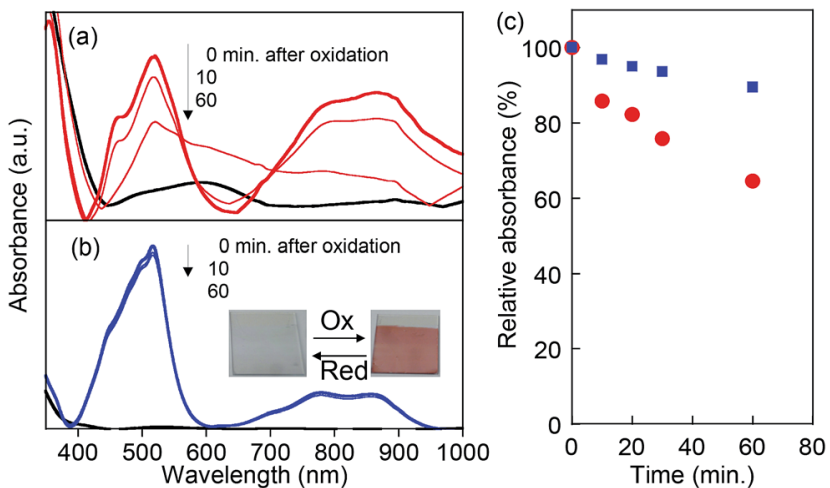

Fig. 3 In situ electrochemical UV spectra of (a) PVBPT and (b) PVPPP on ITO electrode. A neutral phenothiazine form was shown in black, and the corresponding radical cations under the applied potentials at $1.1 \mathrm{~V}$ were shown in red and blue, respectively. (c) Time decay of the relative absorbance at $518 \mathrm{~nm}$ ascribed to the radical cations for PVBPT (red) and PVPPP (blue).

original peak intensity, which indicated the time decay was a reversible process. On the other hand, the absorption peak for PVPPP remained almost unchanged over time, which indicates that the long spacer group contributes the radical stability.

To examine the applicability of both phenothiazine-based polymers as cathode-active materials, chronopotentiometry (CP) experiments were performed. Each polymer was combined with vapor-grown carbon fibers as conductive additives, and poly(vinylidene fluoride) as a binder, and coated on glassy carbon electrode or aluminum foil to prepare the composite electrode. PVPPP electrode exhibited a charging capacity of $Q_{\mathrm{c}}=75 \mathrm{Ah} \mathrm{kg}^{-1}$ and a discharging capacity of $Q_{\mathrm{d}}=72 \mathrm{Ah} \mathrm{kg}^{-1}$ at a C-rate of $10 \mathrm{C}$, which corresponded to $96 \%$ and $92 \%$ of the theoretical calculation (Fig. 4). The coulomb efficiency (ratio of $Q_{\mathrm{d}} / Q_{\mathrm{c}}$ ) was approximately $97 \%$ at all C-rates showing a quantitative redox process in both directions. The plateau voltages slightly increased from 0.85 to $0.93 \mathrm{~V}$ at increasing C-rate from 10 to $50 \mathrm{C}$, and the measured charge capacity decreased to $56 \mathrm{Ah} \mathrm{kg}^{-1}$ (ca. 25\% decrease compared with the initial capacity) at $50 \mathrm{C}$. However, an almost quantitative charging and discharging was achieved up to 20 C-rates. On the other hand, $Q_{c}$

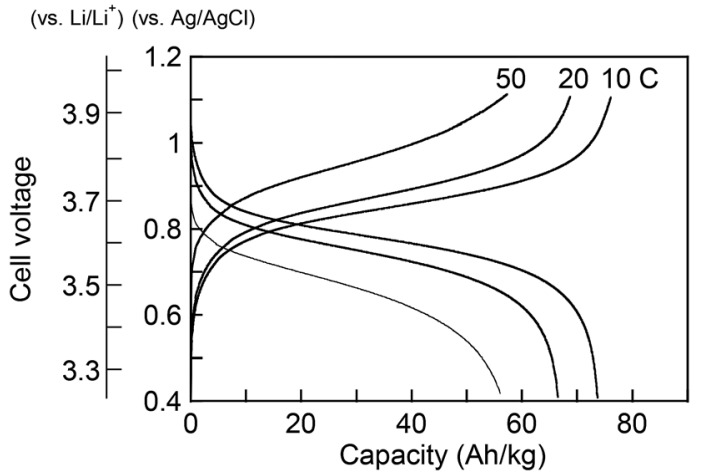

Fig. 4 Charge-discharge curves of PVPPP composite electrodes on glassy carbon.

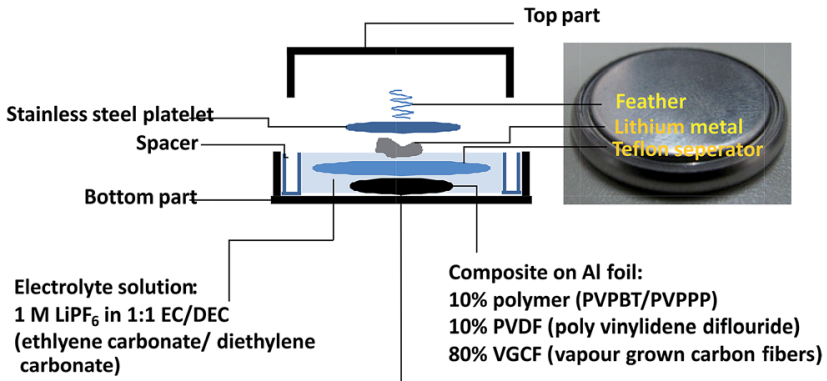

Fig. 5 Schematic setup of a coin cell battery with PVBPT and PVPPP as cathode-active material.

and $Q_{\mathrm{d}}$ for PVBPT were 79 and $61 \mathrm{Ah} \mathrm{kg}^{-1}$, respectively, resulting in $77 \%$ coulomb efficiency. Such self-discharge phenomena can be explained by the lower stability of phenothiazine cation radical for PVBPT with a short spacer group.

To examine the long-term cycle performance of the polymers, PVBPT and PVPPP composite electrodes were installed as a cathode in a coin cell battery with lithium metal anode (Fig. 5). Both polymers demonstrated plateau voltages of around $3.7 \mathrm{~V}$, which was advantageous for high voltage battery devices. The overall cell potential increased around $0.2 \mathrm{~V}$ compared to nitroxide-based polymer cathodes. ${ }^{17}$ The coin cell battery was tested by 500 cycles of sequential charging and discharging CP experiments (Fig. S1 $\dagger$ ). While after 500 cycles the capacity of PVPPP decreased $12 \%$ compared to the initial capacity, PVBPT showed a decrease of $27 \%$. The increase in cycle stability can be attributed to the resonance stabilizing effect of the propylene spacer in PVPPP. The non-branched alkyl spacer stabilizes the radical cation species in the oxidized, coplanar state of phenothiazine.

\section{Conclusions}

In summary, we could successfully integrate polymers with phenothiazine redox moieties as p-type cathode-active material in a lithium coin cell battery. We obtained a high cell voltage of $\sim 3.7 \mathrm{~V}$ by using a phenothiazine-based cathode. This value is promising for utilization in a polymer-based rechargeable battery. One important finding in our study is related to the effect of spacer between the phenothiazine moiety and the polymer backbone. The increase in spacer length decreased the electron self-exchange rate but simultaneously stabilized the radical cation formed by oxidation, resulting in decelerated selfdischarge and improved cycle performance. Our findings offer new molecular design approaches to tune redox stability. Further optimization of cell configuration and electrolyte conditions will be discussed in future studies.

\section{Acknowledgements}

This project was partially supported by the Strategic Japanese German 756 Cooperative Programme On Nanoelectronics (BE3286/2-1; 757 GU 771/6-1), The Japan Science and Technology Agency (JST), and the International Research Training 
Group 1404 "Self-organized Materials for Optoelectronics" (DFG). This project was partially supported by Grants-in Aid for Scientific Research (nos 24225003 and 25620179) from MEXT, Japan. T. S. acknowledges the MEXT/JST tenure-track program.

\section{Notes and references}

1 For reviews and book chapters: (a) H. Nishide and T. Suga, Electrochem. Soc. Interface, 2005, 14(4), 32; (b) K. Nakahara, K. Oyaizu and H. Nishide, Chem. Lett., 2011, 40, 222; (c) P. Poizot and F. Dolhem, Energy Environ. Sci., 2011, 4, 2003; (d) T. Janoschka, M. D. Hager and U. S. Schubert, Adv. Mater., 2012, 24, 6397.

2 H. Nishide and K. Oyaizu, Science, 2008, 319, 737.

3 Z. Gomurashvili and J. V. Crivello, Macromolecules, 2002, 35, 2962.

4 N. J. Treat, H. Sprafke, J. W. Kramer, P. G. Clark, B. E. Barton, J. R. de Alaniz, B. P. Fors and C. J. Hawker, J. Am. Chem. Soc., 2014, 136, 16096.

5 C. Korth, B. C. H. May, F. E. Cohen and S. B. Prusiner, Proc. Natl. Acad. Sci. U. S. A., 2001, 98, 9836.

6 (a) S. K. Kim, J. H. Lee and D. H. Hwang, Synth. Met., 2005, 152, 201; (b) D.-H. Hwang, S.-K. Kim, M.-J. Park, J.-H. Lee, B.-W. Koo, I.-N. Kang, S.-H. Kim and T. Zyung, Chem. Mater., 2004, 16, 1298.

7 E. Dominiquez, H. L. Lan, Y. Okamoto, P. D. Hale, T. A. Skotheim, L. Gorton and B. Hahnhagerdal, Biosens. Bioelectron., 1993, 8, 229.

8 F. Fungo, S. A. Jenekhe and A. J. Bard, Chem. Mater., 2003, 15, 1264.

9 G. P. Brown and S. Aftergut, Nature, 1962, 193, 361.

10 J. P. Billon, Bull. Soc. Chim. Fr., 1960, 1784.

11 (a) Z. Zhou, A. W. Franz, M. Hartmann, A. Seifert, T. J. J. Müller and W. R. Thiel, Chem. Mater., 2008, 20, 4986; (b) Z. Zhou, A. W. Franz, S. Bay, B. Sarkar, A. Seifertm, P. Yang, A. Wagener, S. Ernst, M. Pagels, T. J. J. Müller and W. R. Thiel, Chem.-Asian J., 2010, 5, 2001; (c) M. Sailer, A. W. Franz and T. J. J. Müller, Chem.Eur. J., 2008, 14, 2602; (d) T. J. J. Müller, A. W. Franz,
C. S. Barkschat, M. Sailer, K. Meerholz, D. Müller, A. Colsmann and U. Lemmer, Macromol. Symp., 2010, 287, 1. 12 A. A. Golriz, T. Kaule, J. Heller, M. B. Untch, P. Schattling, P. Theato, M. Toda, S. Yoshida, T. Ono, H. J. Butt, J. S. Gutmann and R. Berger, Nanoscale, 2011, 3, 5049.

13 A. A. Golriz, T. Kaule, M. B. Untch, K. P. Kolman, R. Berger and J. S. Gutmann, ACS Appl. Mater. Interfaces, 2013, 5, 2485.

14 R. Berger, H.-J.- Butt, M. Retschke and S. Weber, Macromol. Rapid Commun., 2009, 30, 1167.

15 R. Berger, Y. Cheng, R. Förch, B. Gotsmann, J. S. Gutmann, T. Pakula, U. Rietzler, W. Schärtl, M. Schmidt, A. Strack, J. Windeln and H.-J. Butt, Langmuir, 2007, 23, 3150.

16 S. A. Pihan, S. G. J. Emmerling, H.-J. Butt, J. S. Gutmann and R. Berger, Wear, 2011, 271, 2852.

17 H. Nishide, S. Iwasa, Y. J. Pu, T. Suga, K. Nakahara and M. Satoh, Electrochim. Acta, 2004, 50, 827.

18 T. Suga, H. Ohshiro, S. Sugita, K. Oyaizu and H. Nishide, $A d v$. Mater., 2009, 21, 1627.

19 W. Choi, D. Harada, K. Oyaizu and H. Nishide, J. Am. Chem. Soc., 2011, 133, 19839.

20 M. Armand, S. Grugeon, H. Vezin, S. Laruelle, P. Ribiere, P. Poizot and J. M. Tarascon, Nat. Mater., 2009, 8, 120.

21 T. Suga, S. Sugita, H. Ohshiro, K. Oyaizu and H. Nishide, Adv. Mater., 2011, 23, 751.

22 T. Suga, Y.-J. Pu, S. Kasatori and H. Nishide, Macromolecules, 2007, 40, 3167.

23 Y. Morishima, I. Akihara, H. S. Lim and S.-I. Nozakura, Macromolecules, 1987, 20, 978.

24 D. Clarke, B. C. Gilbert, P. Hanson and C. M. Kirk, J. Chem. Soc., Perkin Trans. 2, 1978, 1103.

25 K. Oyaizu, Y. Ando, H. Konishi and H. Nishide, J. Am. Chem. Soc., 2008, 130, 14459.

26 (a) H. J. Dahms, J. Phys. Chem., 1968, 72, 362; (b) I. Ruff and V. J. J. Friedrich, J. Phys. Chem., 1971, 75, 3297.

27 D. Sun, S. V. Rosokha and J. K. Kochi, J. Am. Chem. Soc., 2004, 126, 1388.

28 L. Levy, T. N. Tozer, L. D. Tuck and D. B. Loveland, J. Med. Chem., 1972, 15, 898. 